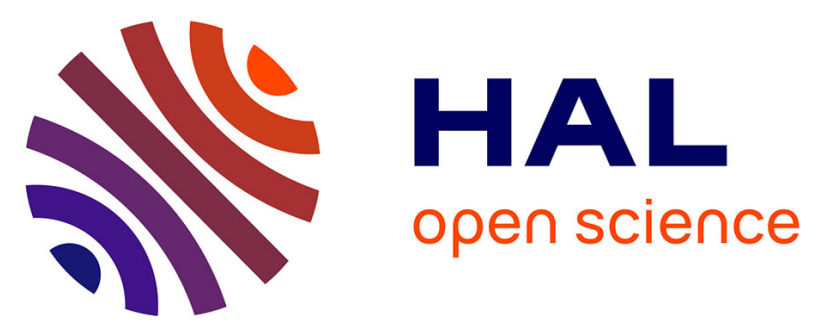

\title{
Metastatic Clear-cell Renal Cell Carcinoma With a Long-term Response to Sunitinib A Distinct Phenotype Independently Associated With Low PD-L1 Expression
}

S.-F. Kammerer-Jacquet, A. Brunot, M. Lefort, Sahar Bayat, B. Peyronnet, G. Verhoest, R. Mathieu, A. Lespagnol, J. Mosser, B. Laguerre, et al.

\section{To cite this version:}

S.-F. Kammerer-Jacquet, A. Brunot, M. Lefort, Sahar Bayat, B. Peyronnet, et al.. Metastatic Clearcell Renal Cell Carcinoma With a Long-term Response to Sunitinib A Distinct Phenotype Independently Associated With Low PD-L1 Expression. Clinical Genitourinary Cancer, 2019, 17 (3), pp.169-176.e1. 10.1016/j.clgc.2019.01.014 . hal-02076598

HAL Id: hal-02076598

https://hal-univ-rennes1.archives-ouvertes.fr/hal-02076598

Submitted on 15 Apr 2019

HAL is a multi-disciplinary open access archive for the deposit and dissemination of scientific research documents, whether they are published or not. The documents may come from teaching and research institutions in France or abroad, or from public or private research centers.
L'archive ouverte pluridisciplinaire HAL, est destinée au dépôt et à la diffusion de documents scientifiques de niveau recherche, publiés ou non, émanant des établissements d'enseignement et de recherche français ou étrangers, des laboratoires publics ou privés. 


\section{Metastatic clear cell renal cell carcinoma with a long-term response to sunitinib: a distinct phenotype independently associated with low PD-L1 expression}

Solène-Florence Kammerer-Jacquet ${ }^{1,2}$, Angelique Brunot ${ }^{3}$, Mathilde Lefort ${ }^{4}$, Sahar Bayat ${ }^{4}$,

Benoit Peyronnet ${ }^{5}$, Gregory Verhoest ${ }^{5}$, Romain Mathieu ${ }^{5}$, Alexandra Lespagnol ${ }^{6}$, Jean Mosser $^{6}$, Brigitte Laguerre ${ }^{3}$, Alain Ravaud ${ }^{7}$, Jean-Christophe Bernhard ${ }^{8}$, Frantz Dupuis ${ }^{9}$, Mokrane Yacoub ${ }^{9}$, Marc-Antoine Belaud-Rotureau ${ }^{2,10}$, Karim Bensalah ${ }^{5}$ et Nathalie RiouxLeclercq $^{1,2}$

Short title: Long-term responders in renal carcinoma

\section{Affiliations :}

1- Université de Rennes 1, Université Bretagne Loire, Service d'Anatomie et Cytologie Pathologiques, F-35042 Rennes, France

2- UMR 6290-IGDR, Rennes, France

3- Service d'Oncologie Médicale, Centre Eugène Marquis, Rennes, France

4- Ecole des Hautes Etudes en Santé Publique (EHESP), Rennes, France

5- Université de Rennes 1, Université Bretagne Loire, Service d’Urologie, F-35042 Rennes, France

6- Université de Rennes 1, Université Bretagne Loire, Service de Génétique Somatique des Cancers, F-35042 Rennes, France

7- Service d'Oncologie Médicale, CHU Saint-André, Bordeaux, France

8- Service d'Urologie, CHU Pellegrin, Bordeaux, France

9- Service d'Anatomie et Cytologie Pathologiques, CHU Pellegrin, Bordeaux, France

10- Université de Rennes 1, Université Bretagne Loire, Service de cytogénétique, F-35042 Rennes, France 


\section{Corresponding author:}

Solene-Florence Kammerer-Jacquet

Service d'Anatomie Pathologique

CHU Pontchaillou

2 rue Henri Le Guilloux

35033 Rennes cedex 9

Telephone number: 0033299284279

Fax number: 0033299284284

Email address: jacquet.sf@gmail.com

Word count of text: 4008 words

Word count of the abstract: 243 words 


\title{
MICROABSTRACT
}

Long-term responders (LTR) are defined by at least 18 months of response to sunitinib in metastatic clear cell renal cell carcinoma (ccRCC). Well described by clinical studies, the phenotype of these tumours has never been explored. Primary tumour of LTR demonstrated a different phenotype with PD-L1 low expression suggesting a potentially lower impact of targeted immunotherapy in these patients.

\begin{abstract}
Background: Long-term responders (LTR) are defined by at least 18 months of response to sunitinib in metastatic clear cell renal cell carcinoma (ccRCC). Well described by clinical studies, the phenotype of these tumours has never been explored.
\end{abstract}

Patients and methods: In a retrospective and multicentre study, $90 \mathrm{ccRCC}$ of metastatic patients were analysed. Immunohistochemistry (CAIX, VEGF, c-MET, PD-L1 and PD-1), VHL status were performed. Progression free survival (PFS) and overall survival (OS) were calculated from sunitinib introduction and from progression. LTR and their corresponding tumours were compared to others using univariate and multivariate analysis.

Results: Twenty-eight patients were LTR. They had a median PFS of 28 versus (vs) 4 months for other patients $(p<0.001)$. Similarly, LTR had a median OS of 49 vs 14 months $(p<0.001)$, even from progression (median 21 vs 7 months, $\mathrm{p}=0.029$ ). They were associated with a favourable or intermediate risk (IMDC model) $(\mathrm{p}=0.007)$ and less liver metastasis $(\mathrm{p}=0.036)$. They experienced more frequent complete or partial responses at the first radiologic evaluation $(\mathrm{p}=0.035)$. The corresponding $\mathrm{ccRCC}$ were associated with less nucleolar ISUP grade $4(\mathrm{p}=0.037)$ and hilar fat infiltration $(\mathrm{p}=0.006)$. They were also associated with low PDL1 expression ( $\mathrm{p}=0.02)$. Only IMDC model and PD-L1 expression remained significant after multivariate analysis $(\mathrm{p}=0.014$ and $\mathrm{p}=0.029$, respectively).

Conclusion: Primary tumour characteristics of LTR were studied for the first time and demonstrated a different phenotype. Interestingly, they were characterized by low expression of PD-L1, suggesting a potentially lower impact of targeted immunotherapy in these patients.

Key words: renal cell carcinoma, sunitinib, PD-L1, long-term responders 


\section{INTRODUCTION}

Clear cell renal cell carcinoma (ccRCC) is the most common histological subtype of renal cancer $(70 \%){ }^{1}$ Along with hereditary ccRCC, sporadic ccRCC is also frequently characterized by an alteration of the $V H L$ gene, a tumour suppressor gene, leading to the transcription of genes regulated by HIF such as VEGF, which triggers the angiogenic process. ${ }^{2}$ In $20 \%$ of patients, ccRCC is diagnosed at metastatic stage and $30 \%$ of the remaining patients will further develop metastases detected during follow-up. With an approximately $50 \%$ risk of metastasis, the prognosis of ccRCC is poor, and the mortality rate is $40 \%$ at 5 years. ${ }^{3}$

Anti-angiogenic therapies have significantly improved the prognosis of patients with metastatic clear cell renal cell carcinoma (ccRCC). ${ }^{4}$ Sunitinib, a tyrosine kinase inhibitor (TKI) targeting VEGFR, is currently an approved first-line treatment option for patients and is the most commonly administered treatment worldwide. ${ }^{5,6}$ However, up to $30 \%$ patients experience progressive disease (PD) upon response evaluation criteria in solid tumours (RECIST) at their first evaluation and most patients ultimately develop PD. ${ }^{7}$ Although several resistance mechanisms have been described, few molecular markers of sensitivity or primary resistance with a prognostic impact have been identified. ${ }^{8}$

Another treatment approach is based on targeted immunotherapy using checkpoint inhibitors because ccRCC is considered an immunogenic tumour with high numbers of mononuclear immune cells such as tumour-infiltrating lymphocytes (TIL). ${ }^{9-11}$ PD-L1 is a transmembrane protein which binds to its co-stimulatory receptor, PD-1 (B7-1), expressed by activated TILs, as a means to down-regulate antitumour immune responses by promoting TIL apoptosis and thus favour tumour progression. Recent clinical trial (Checkmate 025) demonstrated the superiority of anti-PD-1 (nivolumab) over everolimus in second-line treatment. ${ }^{12}$ Following the results of Checkmate 214, the combination of nivolumab plus ipilimumab is now recommended as first-line therapy for patients with intermediate or poor prognosis according to International Metastatic Renal Cell Carcinoma Database Consortium (IMDC) model. ${ }^{13,14}$

Although numerous studies have focused on primary refractory patients defined by progression within the first 3 months, few have studied LTR. ${ }^{15}$ Molina et al. defined longterm response as a durable complete response or remaining progression-free for more than 18 
months and clinically characterized them without assessing the phenotype of the tumours. ${ }^{16}$ With the advent of new treatment in ccRCC, it is crucial to better identify them as these patients are the most likely to benefit from sunitinib. ${ }^{13}$

In this study, we aimed to describe the pathological and immunohistochemical phenotype and VHL status of ccRCC and the clinical outcome of patients according to their long-term responder status.

\section{MATERIAL AND METHODS}

\section{$\underline{\text { Patient selection and classification }}$}

Primary ccRCC-specimens were collected from patients undergoing nephrectomy in two French University Hospitals (Rennes and Bordeaux) from 1997 to 2013 with metastases either at diagnosis or during the follow up. For inclusion in the study, patients with metastatic ccRCC received sunitinib $(50 \mathrm{mg} / \mathrm{day}$, four weeks-on/two weeks-off) as first-line treatment (prior cytokine therapy was allowed) and completed at least one 28-day cycle of sunitinib, and undergone their first CTscan assessment with Response Evaluation Criteria In Solid Tumours (RECIST 1.1). ${ }^{17}$ Drug schedule and dose-reduction policy complied with local practice guidelines. Follow-up chest/abdomen CT-scans were performed every 2 cycles of treatment (3 months). LTR were defined by at least 18 months of treatment without any progression. ${ }^{16}$ For each patient, the following clinical and pathologic information was gathered (using data base UroCCR): age, sex, the six factors in the IMDC model (anaemia, thrombocytosis, neutrophilia, Karnofsky performance status $<80,<1$ year from diagnosis to first-line targeted therapy and hypercalcemia) before sunitinib introduction, pTNM stage at nephrectomy, tumour size, and nucleolar ISUP grade. ${ }^{18,} 19$ Histopathologic assessment was performed by three experienced pathologists (SFKJ, MY and NRL). For each patient, frozen ccRCC were available. Informed consent was signed from each patient and institutional review board approval was obtained for this study (CNIL declaration receipt 1812601v0).

\section{$\underline{\text { Immunohistochemical study }}$}

For each primary tumour, a representative slide of the tumour with the highest nucleolar grade and the corresponding paraffin block was selected. Four $\mu$ m-thick whole tissue sections were cut and mounted on glass slides (Superfrost + , Menzel Glazer). The preparations were dried for 1 hour at $58^{\circ} \mathrm{C}$, and then overnight at $37^{\circ} \mathrm{C}$. The sections were deparaffinized with toluene 
and rehydrated with ethanol. The preparations were pretreated and immunostained using Ventana Benchmark XT. VEGFA (Anti-VEGF antibody, sc-152, dilution 1/100 ; Santa Cruz Biotechnology, Santa Cruz, CA, USA), CAIX (Anti-CAIX antibody, ab15086, dilution 1/1500, Abcam, Cambridge, UK), c-MET (Anti-Total c-MET, SP44, Rabbit Monoclonal Primary Antibody, ready-diluted, Ventana, Roche, Switzerland), PD-L1 (Anti-PD-L1 antibody, clone 130021, dilution 1/200, RD System, Minneapolis, USA) and PD1 (anti-PD-1 antibody, clone NAT105, dilution 1:50; Abcam, Cambridge, UK) expressions were assessed by immunohistochemistry as previously described. ${ }^{20-22}$ The reactivity of antibodies was revealed with HRP-labeled polymer conjugated secondary antibodies using diaminobenzidine (DAB) as chromogen (Sigma-Aldrich, France). Negative controls were performed by omitting the primary antibody. The tumour expression for each antibody was independently evaluated (SFKJ and NRL), without knowledge of the case. The cut-off for positive cases was $30 \%$ of tumour cells for VEGF and $85 \%$ for CAIX as previously described. ${ }^{20,21}$ For PD-L1 and MET, absent (0), weak (1), moderate (2) and strong expression (3) were reported and cases were then subdivided into negative $(0-1)$ or positive (2-3) subgroups. $^{22,} 23$ For PD-1, immunostaining density was evaluated in tumour infiltrating lymphocytes and was semiquantified as absent, rare, moderate or dense as previously reported. ${ }^{24}$

\section{$\underline{\text { VHL status }}$}

\section{Next generation sequencing}

For $V H L$ gene, the entire coding sequence and exon-intron junctions of exons 1, 2 and 3 were analyzed. Genomic DNA was extracted using Magtration System 12GC (Bionobis) according to the manufacturer's instruction. Genomic DNA from all samples was quantitated with the Quan-iT PicoGreen dsDNA assay kit (Thermo Fisher Scientific). DNA target preparation and enrichment were performed by amplification using the Access Array® system (Fluidigm, San Francisco, USA). A 10-nucleotide "barcode" tag, specific to each sample and Illuminaspecific sequencing adaptors were attached using secondary PCR. Purified products were then pooled and sequenced on the Illumina MiSeq NGS instrument (Illumina Inc., San Diego, California).

\section{Multiplex Ligation-dependent Probe Amplification}

Methylation-Specific-MLPA (MS-MLPA) was used to detect $\mathrm{CpG}$ methylation islands in VHL gene promotor. The SALSA MS-MLPA kit ME001B Tumour suppressor-1 allows detecting aberrant methylation of CpG-Islands located in the promoter region of the $V H L$ gene. $^{25}$ The unmethylated DNA will not generate a signal, and a normal probe signal will be 
detected if the site is methylated.

\section{$\underline{\text { Statistical analysis }}$}

The phenotype of ccRCC (histologic and immunohistochemical features, VHL status in long term responders) was compared with other patients. Associations were analyzed with $\chi^{2}$, Fisher and Mann-Whitney tests. For logistic regression, we used a backward stepwise selection with $\mathrm{p}<0.05$ inclusion criteria. The rank of elimination was obtained when a variable was removed from the equation, and the odds ratio, 95\% CI, and p-value for the removed variables were obtained on the removal step. For clinical outcome, we represented progression-free survival (PFS) from the sunitinib introduction to progression and overall survival (OS) from sunitinib introduction to death using Kaplan-Meier curves. We also represented PFS starting from 18 months for LTR and OS from progression to death. All pvalues were 2 -sided, and p-values less than 0.05 were considered statistically significant. All statistical analyses were performed using Stata 14.1 (College Station, TX) software.

\section{RESULTS}

\section{$\underline{\text { Patient and tumour characteristics }}$}

Patient and tumour characteristics are presented in Table 1. The study retrospectively included 90 consecutive metastatic patients with primary ccRCC. The mean follow-up period was 25 months (range 1-76 months) from sunitinib introduction. The median PFS and OS were 10 and 22 months, respectively. Eighty-five patients (94.4\%) experienced progression and 71 (78.9\%) died from their cancer. Men were most represented (62.2\% versus 37.8\%). According to the IMDC model, most patients were in the intermediate group (47.7\%). Locally advanced tumours were mostly represented (stage pT3-T4 in 75.5\% of patients), and showed a high nucleolar ISUP grade 3 or $4(n=88,92.3 \%)$. Metastases were present at the initial diagnosis for $55.6 \%$ of patients. More than two-third of patients presented multiple metastatic sites $(\mathrm{n}=69 ; 76.7 \%)$. The most common metastatic sites were lung $(75.6 \%)$, bone $(53.3 \%)$ and liver $(23.3 \%)$.

\section{$\underline{\text { VHL status }}$}

VHL status was assessed in the entire cohort $(n=90)$. All patients were negative for germ-line mutations. A VHL gene mutation was observed in 64 cases $(71.1 \%)$. Mutations occurred in exons 1,2 and 3 in 28 (43.8\%), 21 (32.8\%) and 15 cases (23.4\%) respectively. Stop, 
frameshift, missense, and splice site mutations were detected in 8 (12.5\%), 34 (53.1\%), 18 (28.1\%) and $4(6.3 \%)$ cases respectively. VHL promoter methylation occurred in 10 cases (11.1\%). At least one or more $V H L$ abnormalities (VHL inactivation) were observed in 74 cases $(82.2 \%)$.

\section{Correlation with clinical outcome}

Twenty-eight patients were LTR and belonged to good $(n=10)$, intermediate $(n=15)$ and poor $(\mathrm{n}=3)$ risks according to IMDC score. Among LTR, 23 patients progressed and 13 received second-line therapy (everolimus, $\mathrm{n}=5$; pazopanib, $\mathrm{n}=3$; sorafenib, $\mathrm{n}=3$; axitinib, $\mathrm{n}=2$ ), 7 received third-line therapy (everolimus, $n=5$; sorafenib, $n=1$ and axitinib, $n=1$ ) and 1 received a fourth-line therapy by pazopanib. Twelve patients were last known to be alive with a continuing response or stable disease. Kaplan Meier curves for PFS and OS are presented in Figures 1, 2 and 3. LTR had a median PFS of 28 months versus 4 months for other patients ( $p<0.001$ ). Similarly, LTR had a median OS of 49 months versus 14 months for other patients ( $\mathrm{p}<0.001)$. From progression, LTR still had a difference of survival, median OS of 21 versus 7 months $(\mathrm{p}=0.29)$.

\section{Pathological, immunohistochemical phenotype and VHL status of LTR}

LTR had good or intermediate prognosis according to the IMDC model $(\mathrm{p}=0.007)$ and less liver metastasis $(\mathrm{p}=0.036)$ (Table 2). They more frequently experienced a complete or partial response at the first radiologic evaluation $(\mathrm{p}=0.035)$. Corresponding $\mathrm{ccRCC}$ were associated with less nucleolar ISUP grade $4(\mathrm{p}=0.037)$ and less hilar fat infiltration $(\mathrm{p}=0.006)$. They were also associated with low expression of PD-L1 by immunohistochemistry ( $\mathrm{p}=0.02)$, Figure 4. No association with $V H L$ status was identified. All the significant variables were included for logistic regression except liver metastases that could interfere with Heng score criteria. The only 2 factors that remained significantly associated with LTR were good or intermediate risk (IMDC model) $(\mathrm{p}=0.014$, OR $(95 \% \mathrm{CI})=5.29(1.39,20.01))$ and low PD-L1 expression $(\mathrm{p}=0.029$, OR $(95 \% \mathrm{CI})=3.145(1.22,8.31))$, Table 3 .

\section{DISCUSSION}

To our knowledge, this is the first study to assess the phenotype of ccRCC in LTR along with a long term clinical follow-up. Previous studies identified clinic-biological criteria associated with LTR. 
Molina et al. described for the first time the patients who benefit the most from sunitinib at clinical level ${ }^{16}$. This retrospective study $(n=186)$ mainly included ccRCC but also other subtypes representing $12 \%$ of their cohort even though their carcinogenesis was different. Moreover, the majority of them $(52.1 \%)$ received sunitinib in combination with gefitinib, bevacizumab or everolimus whose targets were not the same. In their study, favourable Memorial Sloan Kettering Cancer Center (MSKCC) score was associated with LTR.

A recent study by Escudier et al. proposed a pooled analysis of clinical trials including retrospectively 5714 patients. ${ }^{26}$ Among them, 897 (15.7\%) patients were LTR. They were associated with higher percentage of early tumour shrinkage at the first scan, white race, favourable criteria of IMDC mode, clear cell histology, no liver metastasis, body mass index $\geq 25 \mathrm{~kg} / \mathrm{m}^{2}$.

Similarly, in our study, LTR exhibited good or intermediate prognosis (IMDC model related to MSKCC), which remained unsurprisingly significant after multivariate analysis. Moreover, they had significantly fewer liver metastases than other patients. Indeed, liver metastases were previously associated with poor prognosis in patients with metastatic ccRCC and the absence of liver metastases was already correlated to LTR. ${ }^{26,27}$ McKay et al previously described that their impact was attributed to alteration of sunitinib metabolism and the liver microenvironment that could favour an aggressive phenotype. ${ }^{27}$

One limitation of our study is the selection of 18 months as a cut-off to define LTR but was reproducible with previous studies. ${ }^{16,26}$ Another limitation is our sample size impairing multivariate analysis. However, contrary to previous studies, we included only clear cell histology and performed a pathological and immunohistochemical study with VHL status on primary tumours along with clinical data.

At molecular level, VHL was inactivated by mutually exclusive mutation or promoter methylation in the majority of cases without any association with the sunitinib response. As previously described, no association between $V H L$ status and outcome was observed. ${ }^{28,29}$ $V H L$ inactivation, considered as an archetypical tumour-initiating event in ccRCC carcinogenesis, failed to identify sunitinib responders, as other mechanisms probably interfere.

We report a distinct pathological and immunohistochemical phenotype of the primary tumours of LTR. As a matter of fact, ccRCC were particularly associated with a lower nucleolar ISUP grade and a less frequent infiltration of hilar fat. They were independently 
associated with lower expression of PD-L1 by immunohistochemistry. First demonstrated in our study, this is consistent with the results of Choueiri et al. who correlated PD-L1 expression with poor outcome in patients with metastatic ccRCC. ${ }^{30}$

Recent update on metastatic ccRCC treatment based on recent Checkmate 214 results recommends a dichotomized approach for first line therapy according to IMDC model. ${ }^{13}$ In intermediate- and poor risk patients, targeted immunotherapies are now indicated whereas in favourable-risk patients, antiangiogenic therapy remains the standard of treatment. In our study, some LTR belonged to intermediate- and poor risk and could have been treated by immunotherapies according to the new standards; however, they clearly benefited from sunitinib. The high expression of PD-L1 associated with better response to immunotherapy in Checkmate 214 trial, could suggest, in LTR associated with low expression of PD-L1, less interest in targeted immunotherapies and reinforce its potential use as predictive biomarker.

Interestingly, the OS was also found to be prolonged in these patients, even from progression. LTR demonstrated an increased overall survival that was not only explained by their response to sunitinib first-line treatment, but also to second-line targeted therapy. The hypothesis could be that these patients who are more than good responders to sunitinib may be likely to do well under other targeted therapy. Further studies could help clarify whether such responses are specific to sunitinib or reflect underlying favourable biology.

In conclusion, LTR showed a prolonged OS even from progression. Their primary tumours demonstrated a different phenotype with PD-L1 low expression suggesting a potentially lower impact of targeted immunotherapy in these patients.

\section{ACKNOWLEDGMENTS}

The authors would like to thank the Ligue Contre le Cancer, CORECT, Rennes Hospital and the French Institute of Cancer (INCa) for their financial support.

The authors would also like to thank the Rennes Hospital Biological Resources Center (BB0033-00056, http://www.crbsante-rennes.com/) for patient sample management as well as Pascale Bellaud and Roselyne Viel from the Histopathology platform H2P2-BIOSIT at the Faculty of Medicine in Rennes for their technical support.

The authors want to thank Nathalie Costet from Team 9, IRSET and Chloé Rousseau from CIC Inserm 1414 for their contribution to statistical analysis.

\section{AUTHORS' CONTRIBUTION}

SF Kammerer-Jacquet, N Rioux-Leclercq: Protocol/project development 
A Brunot, B Peyronnet, G Verhoest, R Mathieu, B Laguerre, A Ravaud, JC Bernhard, F

Dupuis, M Yacoub: Data collection or management

M Lefort, S Bayat, A Lespagnol, J Mosser: Data analysis

SF Kammerer-Jacquet, MA Belaud-Rotureau, N Rioux-Leclercq, K Bensalah: Manuscript writing/editing

\section{DISCLOSURE OF POTENTIAL CONFLICTS OF INTEREST}

The authors declare that they have no conflict of interest.

\section{RESEARCH INVOLVING HUMAN PARTICIPANTS AND/OR ANIMALS}

All procedures performed in studies involving human participants were in accordance with the ethical standards of the institutional and/or national research committee and with the 1964 Helsinki declaration and its later amendments or comparable ethical standards. For this type of study formal consent is not required.

\section{INFORMED CONSENT}

Informed consent was obtained from all individual participants included in the study.

\section{REFERENCES}

1. Srigley JR, Delahunt B, Eble JN, et al. The International Society of Urological Pathology (ISUP) Vancouver Classification of Renal Neoplasia. The American journal of surgical pathology. 2013;37:1469-1489.

2. Gossage L, Eisen T, Maher ER. VHL, the story of a tumour suppressor gene. Nat Rev Cancer. 2015;15:55-64.

3. Ljungberg B, Campbell SC, Choi HY, et al. The epidemiology of renal cell carcinoma. Eur Urol. 2011;60:615-621.

4. Motzer RJ, Bukowski RM. Targeted therapy for metastatic renal cell carcinoma. $J$ Clin Oncol. 2006;24:5601-5608.

5. Motzer RJ, Hutson TE, Tomczak $P$, et al. Sunitinib versus interferon alfa in metastatic renal-cell carcinoma. $N$ Engl J Med. 2007;356:115-124.

6. Miller LA, Stemkowski S, Saverno K, et al. Patterns of Care in Patients with Metastatic Renal Cell Carcinoma Among a U.S. Payer Population with Commercial or Medicare Advantage Membership. J Manag Care Spec Pharm. 2016;22:219-226.

7. Bergers G, Hanahan D. Modes of resistance to anti-angiogenic therapy. Nat Rev Cancer. 2008;8:592-603. 
8. Garcia-Donas J, Esteban E, Leandro-Garcia LJ, et al. Single nucleotide polymorphism associations with response and toxic effects in patients with advanced renal-cell carcinoma treated with first-line sunitinib: a multicentre, observational, prospective study. Lancet Oncol. 2011;12:1143-1150.

9. Leite KR, Reis ST, Junior JP, et al. PD-L1 expression in renal cell carcinoma clear cell type is related to unfavorable prognosis. Diagnostic pathology. 2015;10:189.

10. Thompson RH, Dong H, Kwon ED. Implications of B7-H1 expression in clear cell carcinoma of the kidney for prognostication and therapy. Clin Cancer Res. 2007;13:709s-715s.

11. Thompson RH, Dong H, Lohse CM, et al. PD-1 is expressed by tumor-infiltrating immune cells and is associated with poor outcome for patients with renal cell carcinoma. Clin Cancer Res. 2007;13:1757-1761.

12. Motzer RJ, Escudier B, McDermott DF, et al. Nivolumab versus Everolimus in Advanced Renal-Cell Carcinoma. N Engl J Med. 2015;373:1803-1813.

13. Powles T, Albiges L, Staehler M, et al. Updated European Association of Urology Guidelines Recommendations for the Treatment of First-line Metastatic Clear Cell Renal Cancer. Eur Urol. 2017.

14. Heng DY, Xie W, Regan MM, et al. External validation and comparison with other models of the International Metastatic Renal-Cell Carcinoma Database Consortium prognostic model: a population-based study. Lancet Oncol. 2013;14:141-148.

15. Heng DY, Mackenzie MJ, Vaishampayan UN, et al. Primary anti-vascular endothelial growth factor (VEGF)-refractory metastatic renal cell carcinoma: clinical characteristics, risk factors, and subsequent therapy. Annals of oncology : official journal of the European Society for Medical Oncology / ESMO. 2011;23:1549-1555.

16. Molina AM, Jia X, Feldman DR, et al. Long-term response to sunitinib therapy for metastatic renal cell carcinoma. Clinical genitourinary cancer. 2013;11:297-302.

17. Eisenhauer EA, Therasse $P$, Bogaerts $J$, et al. New response evaluation criteria in solid tumours: revised RECIST guideline (version 1.1). Eur J Cancer. 2009;45:228-247.

18. Ko JJ, Xie W, Kroeger N, et al. The International Metastatic Renal Cell Carcinoma Database Consortium model as a prognostic tool in patients with metastatic renal cell carcinoma previously treated with first-line targeted therapy: a population-based study. Lancet Oncol. 2015;16:293-300. 
19. Delahunt B, Cheville JC, Martignoni G, et al. The International Society of Urological Pathology (ISUP) grading system for renal cell carcinoma and other prognostic parameters. The American journal of surgical pathology. 2013;37:1490-1504.

20. Rioux-Leclercq N, Fergelot P, Zerrouki S, et al. Plasma level and tissue expression of vascular endothelial growth factor in renal cell carcinoma: a prospective study of 50 cases. Human pathology. 2007;38:1489-1495.

21. Patard JJ, Fergelot P, Karakiewicz PI, et al. Low CAIX expression and absence of VHL gene mutation are associated with tumor aggressiveness and poor survival of clear cell renal cell carcinoma. International journal of cancer. Journal international du cancer. 2008; 123:395-400.

22. Shin SJ, Jeon YK, Kim PJ, et al. Clinicopathologic Analysis of PD-L1 and PD-L2 Expression in Renal Cell Carcinoma: Association with Oncogenic Proteins Status. Ann Surg Oncol. 2015.

23. Kammerer-Jacquet SF, Medane S, Bensalah K, et al. Correlation of c-MET Expression with PD-L1 Expression in Metastatic Clear Cell Renal Cell Carcinoma Treated by Sunitinib First-Line Therapy. Target Oncol. 2017;12:487-494.

24. Schmidt LH, Kummel A, Gorlich D, et al. PD-1 and PD-L1 Expression in NSCLC Indicate a Favorable Prognosis in Defined Subgroups. PLoS One. 2015;10:e136023.

25. Jeuken JW, Cornelissen SJ, Vriezen M, et al. MS-MLPA: an attractive alternative laboratory assay for robust, reliable, and semiquantitative detection of MGMT promoter hypermethylation in gliomas. Lab Invest. 2007;87:1055-1065.

26. Tannir NM, Figlin RA, Gore ME, et al. Long-Term Response to Sunitinib Treatment in Metastatic Renal Cell Carcinoma: A Pooled Analysis of Clinical Trials. Clinical genitourinary cancer. 2017.

27. McKay RR, Kroeger N, Xie W, et al. Impact of bone and liver metastases on patients with renal cell carcinoma treated with targeted therapy. Eur Urol. 2014;65:577-584.

28. Rini BI, Jaeger E, Weinberg V, et al. Clinical response to therapy targeted at vascular endothelial growth factor in metastatic renal cell carcinoma: impact of patient characteristics and Von Hippel-Lindau gene status. BJU Int. 2006;98:756-762.

29. Choueiri TK, Vaziri SA, Jaeger E, et al. von Hippel-Lindau gene status and response to vascular endothelial growth factor targeted therapy for metastatic clear cell renal cell carcinoma. The Journal of urology. 2008;180:860-865; discussion 865-866.

30. Choueiri TK, Figueroa DJ, Fay AP, et al. Correlation of PD-L1 Tumor Expression and Treatment Outcomes in Patients with Renal Cell Carcinoma Receiving Sunitinib or 
Pazopanib: Results from COMPARZ, a Randomized Controlled Trial. Clin Cancer Res. 2015;21:1071-1077. 


\section{Tables}

Table 1: Patient and tumour characteristics of 90 metastatic ccRCC .

\begin{tabular}{|c|c|c|}
\hline Characteristics & No & $\%$ \\
\hline Age (years) & \multirow{3}{*}{\multicolumn{2}{|c|}{$\begin{array}{c}61,3 \\
37-85\end{array}$}} \\
\hline Mean & & \\
\hline Range & & \\
\hline \multicolumn{3}{|l|}{ Sexe } \\
\hline Male & 56 & $62,2 \%$ \\
\hline Female & 34 & $37,8 \%$ \\
\hline \multicolumn{3}{|l|}{ IMDC } \\
\hline Favourable & 20 & $22,2 \%$ \\
\hline Intermediate & 43 & $47,8 \%$ \\
\hline Poor & 27 & $30,0 \%$ \\
\hline \multicolumn{3}{|l|}{ T stage } \\
\hline $\mathrm{T} 1$ & 14 & $15,6 \%$ \\
\hline $\mathrm{T} 2$ & 8 & $8,9 \%$ \\
\hline $\mathrm{T} 3$ & 63 & $70,0 \%$ \\
\hline $\mathrm{T} 4$ & 5 & $5,6 \%$ \\
\hline \multicolumn{3}{|l|}{ N stage } \\
\hline No & 75 & $83,3 \%$ \\
\hline $\mathrm{N} 1-\mathrm{N} 2$ & 15 & $16,7 \%$ \\
\hline \multicolumn{3}{|l|}{ M stage } \\
\hline M0 & 40 & $44,4 \%$ \\
\hline M1 & 50 & $55,6 \%$ \\
\hline \multicolumn{3}{|l|}{ Tumor size $(\mathrm{cm})$} \\
\hline Mean & \multicolumn{2}{|c|}{9.6} \\
\hline Range & \multicolumn{2}{|c|}{$2-9.5$} \\
\hline \multicolumn{3}{|l|}{ ISUP nucleolar grade } \\
\hline Grade 2 & 7 & $7,8 \%$ \\
\hline Grade 3 & 33 & $36,7 \%$ \\
\hline Grade 4 & 50 & $55,6 \%$ \\
\hline \multicolumn{3}{|l|}{ RECIST 1} \\
\hline Complete response & 1 & $1,1 \%$ \\
\hline Partial response & 27 & $30,0 \%$ \\
\hline Stable disease & 34 & $37,8 \%$ \\
\hline Progression disease & 28 & $31,1 \%$ \\
\hline
\end{tabular}


Table 2: Comparison between long-term responders and other patients.

\begin{tabular}{|c|c|c|c|c|c|}
\hline Variables & $\begin{array}{c}\text { Long-term } \\
\text { responders } \\
\quad(n=28)\end{array}$ & $\%$ & $\begin{array}{c}\text { Other patients } \\
(n=62)\end{array}$ & $\%$ & p-value \\
\hline \multicolumn{6}{|l|}{ Clinical and radiological data } \\
\hline Male & 20 & $71,4 \%$ & 36 & $58,1 \%$ & $0,226+$ \\
\hline Age $>65$ & 8 & $28,6 \%$ & 29 & $46,8 \%$ & $0,104 \dagger$ \\
\hline Good/intermediate risk (IMDC) & 25 & $89,3 \%$ & 38 & $61,3 \%$ & $0,007+$ \\
\hline Distant lymph node metastasis & 11 & $39,3 \%$ & 28 & $45,2 \%$ & $0,603 \dagger$ \\
\hline Pulmonary metastasis & 20 & $71,4 \%$ & 48 & $77,4 \%$ & $0,54 \dagger$ \\
\hline Bone metastasis & 16 & $57,1 \%$ & 32 & $51,6 \%$ & $0,626 \dagger$ \\
\hline Liver metastasis & 2 & $7,1 \%$ & 19 & $30,6 \%$ & $0,015 \dagger$ \\
\hline Cerebral metastasis & 4 & $14,3 \%$ & 15 & $24,2 \%$ & $0,286 \dagger$ \\
\hline Multiple metastasis & 21 & $75,0 \%$ & 48 & $77,4 \%$ & $0,802 \dagger$ \\
\hline RECIST 1 (CR-PR vs SD-PD) & 13 & $46,4 \%$ & 15 & $24,2 \%$ & $0,035+$ \\
\hline \multicolumn{6}{|l|}{ Pathological analysis } \\
\hline Size $>7 \mathrm{~cm}$ & 16 & $57,1 \%$ & 42 & $67,7 \%$ & $0,331 \dagger$ \\
\hline Nucleolar ISUP grade 4 & 11 & $39,3 \%$ & 39 & $62,9 \%$ & $\mathbf{0 , 0 3 7}+$ \\
\hline Sarcomatoid component & 3 & $10,7 \%$ & 16 & $25,8 \%$ & $0,104 \dagger$ \\
\hline Tumor necrosis & 19 & $67,9 \%$ & 52 & $83,9 \%$ & $0,085 \dagger$ \\
\hline Microvascular invasion & 11 & $39,3 \%$ & 30 & $48,4 \%$ & $0,422 \dagger$ \\
\hline T3-T4 stage & 19 & $67,9 \%$ & 49 & $79,0 \%$ & $0,253 \dagger$ \\
\hline Hilar fat infiltration & 7 & $25,0 \%$ & 35 & $56,5 \%$ & $0,006+$ \\
\hline Peri-renal fat infiltration & 14 & $50,0 \%$ & 31 & $50,0 \%$ & $1 \dagger$ \\
\hline Venal invasion & & $50,0 \%$ & 27 & $43,5 \%$ & $0,569 \dagger$ \\
\hline N1-N2 stage & 3 & $10,7 \%$ & 12 & $19,4 \%$ & $0,375 \ddagger$ \\
\hline M1 stage & 15 & $53,6 \%$ & 35 & $56,5 \%$ & $0,799 \dagger$ \\
\hline \multicolumn{6}{|l|}{ Immunohistochemistry } \\
\hline CAIX $>85 \%$ & 10 & $35,7 \%$ & 18 & $29,0 \%$ & $0,526 \dagger$ \\
\hline VEGFA $>30 \%$ & 12 & $42,9 \%$ & 38 & $61,3 \%$ & $0,103 \dagger$ \\
\hline MET 2-3 intensity & 18 & $64,3 \%$ & 44 & $71,0 \%$ & $0,526 \dagger$ \\
\hline PD-L1 2-3 intensity & 16 & $57,1 \%$ & 50 & $80,6 \%$ & $\mathbf{0 , 0 2} \dagger$ \\
\hline PD-1 moderate or dense & 18 & $64,3 \%$ & 48 & $77,4 \%$ & $0,192 \dagger$ \\
\hline \multicolumn{6}{|l|}{ VHL status } \\
\hline VHL mutation & 20 & $71,4 \%$ & 44 & $71,0 \%$ & $0,964 \dagger$ \\
\hline Promoter methylation & 2 & $7,1 \%$ & 8 & $12,9 \%$ & $0,718 \div$ \\
\hline VHL inactivation & 22 & $78,6 \%$ & 52 & $83,9 \%$ & $0,543 \dagger$ \\
\hline
\end{tabular}

$\dagger, \chi^{2}$ test; + , Fisher exact test

RECIST 1: First RECIST evaluation, CR, complete response; PR, partial response; SD, stable disease; $\mathrm{PD}$, progression disease 
Table 3: Logistic regression with rank of elimination and intermediate results

\begin{tabular}{|l|c|c|c|c|}
\hline \multicolumn{1}{|c|}{ Variables } & Rank & OR & 95\% CI & p-value \\
\hline Good/intermediate prognosis (Heng) & - & 5.292 & $1.399,20.01$ & 0.014 \\
RECIST 1 (CR-PR vs SD-PD) & 3 & 0.389 & $0.139,1.083$ & 0.071 \\
Nucleolar ISUP grade 4 & 1 & 0.509 & $0.182,1.419$ & 0.197 \\
Hilar fat infiltration & 2 & 0.401 & $0.136,1.184$ & 0.098 \\
PD-L1 low intensity & - & 3.145 & $1.122,8.812$ & 0.029 \\
\hline
\end{tabular}

\section{Supplementary table}

\begin{tabular}{|c|c|c|c|c|c|c|}
\hline \multicolumn{2}{|c|}{ Variables } & \multirow[t]{2}{*}{$\begin{array}{c}\text { Long-term responders } \\
\qquad(\mathrm{n}=\mathbf{2 8})\end{array}$} & \multirow[t]{2}{*}{$\%$} & $\begin{array}{c}\text { Short-term responders } \\
(\mathrm{n}=62)\end{array}$ & $\%$ & \multirow[t]{2}{*}{ p-value } \\
\hline Heng score & & & & & & \\
\hline & Favourable & 10 & $35,7 \%$ & 10 & $16,1 \%$ & $0.039 \dagger$ \\
\hline & Intermediate & 15 & $53,6 \%$ & 28 & $45,2 \%$ & $0.46 \dagger$ \\
\hline & Poor & 3 & $10,7 \%$ & 24 & $38,7 \%$ & $0,007 \dagger$ \\
\hline
\end{tabular}


Figure 1: Kaplan Meier curve representing progression-free survival (PFS) and overall survival (OS)

PFS: Median survival: 4 vs 28 months ( $p<0.001)$, OS: median survival: 14 vs 49 months ( $<<0.001)$
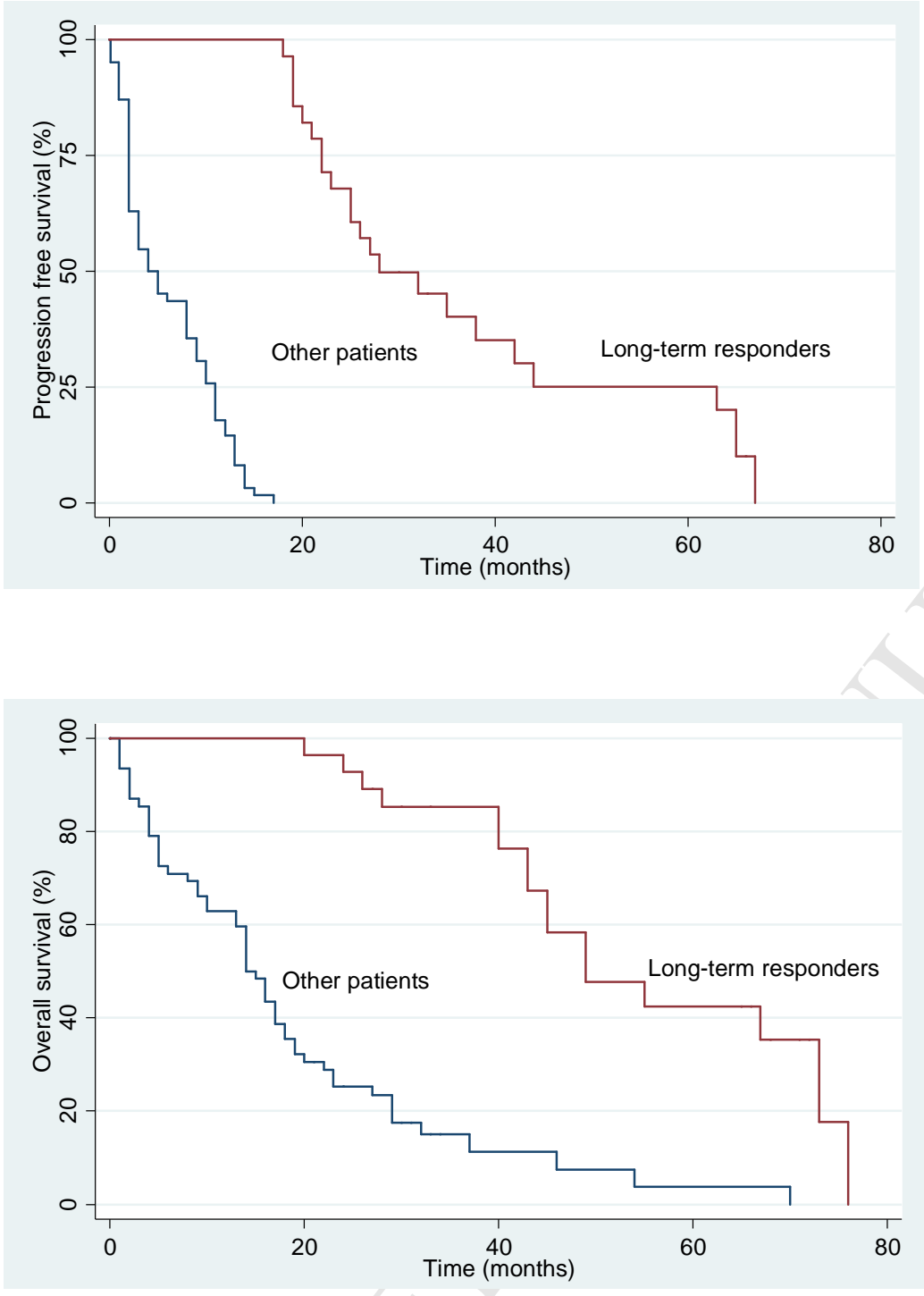
Figure 2: Kaplan Meier curve representing progression free survival of long-term responders $(\mathbf{n}=28)$ with time zero starting at 18 months.

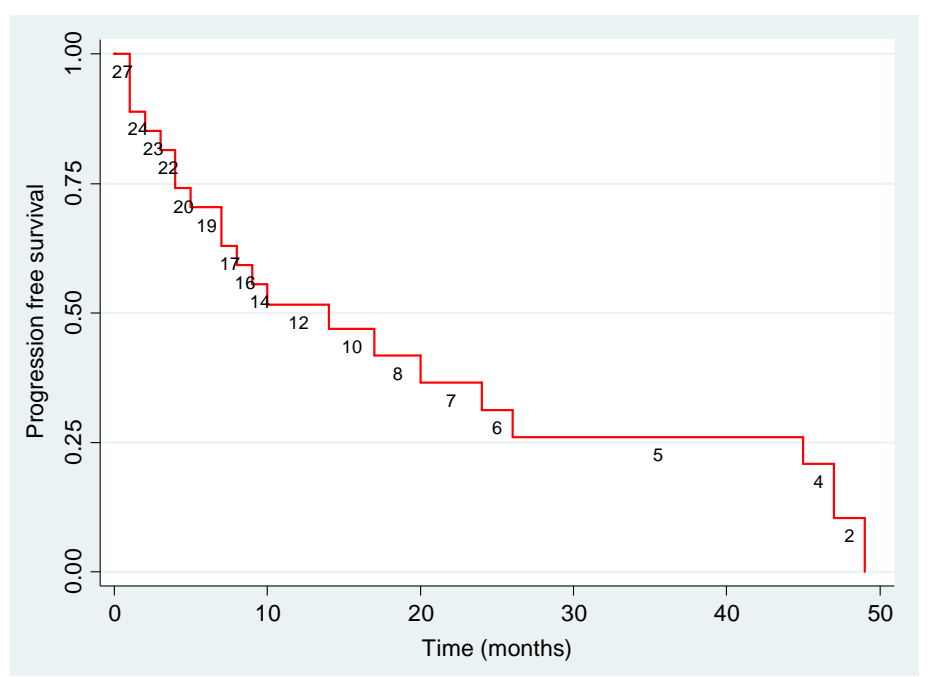

Figure 3: Kaplan Meier curves representing overall survival (OS) from progression.

OS: median survival: 7 vs 21 months $(\mathrm{p}=0.029)$

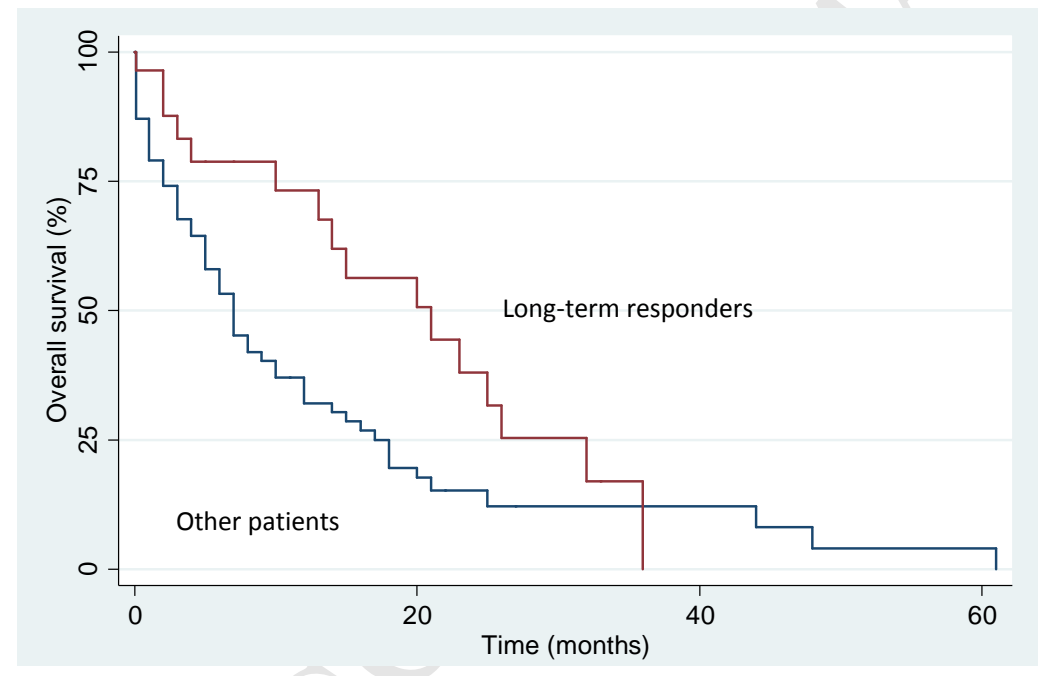




\section{Figure 4: PD-L1 expression}

A- Absence of PDL1 expression, immunohistochemistry (IHC) x100

B- Low expression of PDL1, IHC x100

C- Moderate expression of PDL1, IHC x100

D- High expression of PDL1, IHC x100
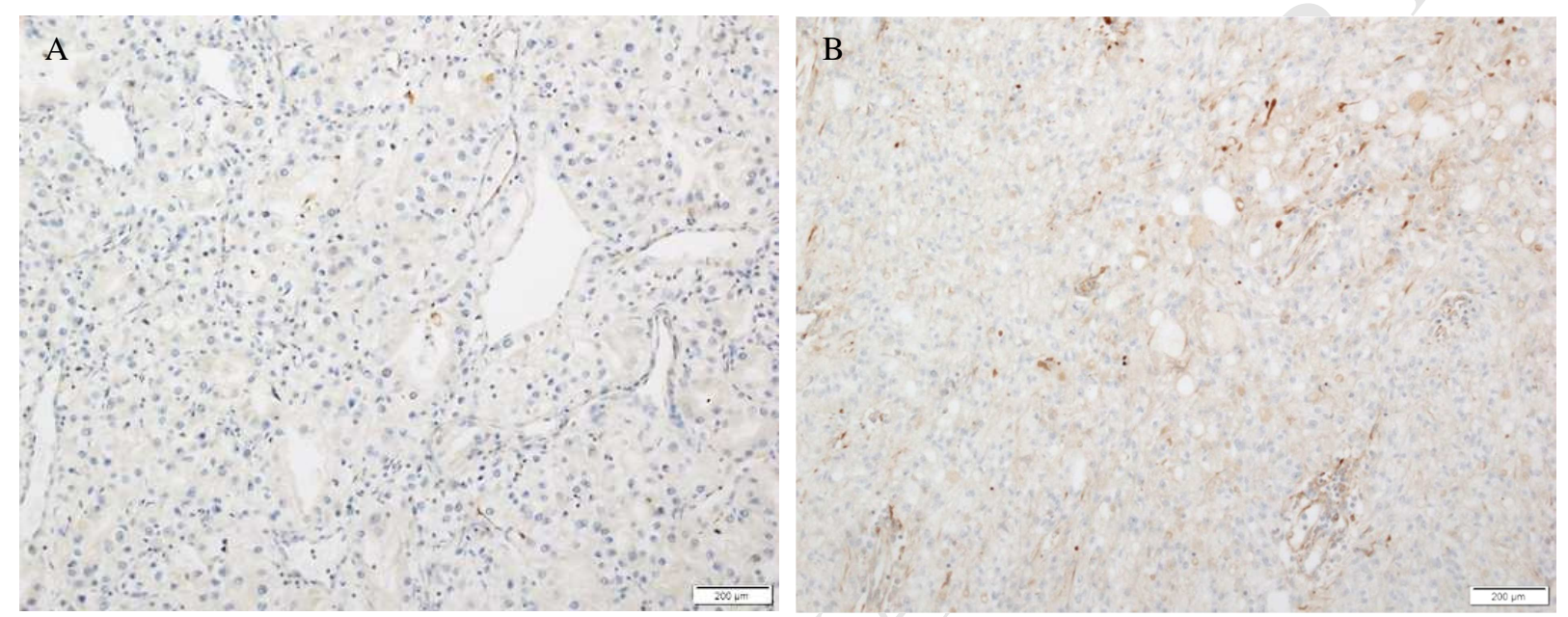

$\mathrm{C}$
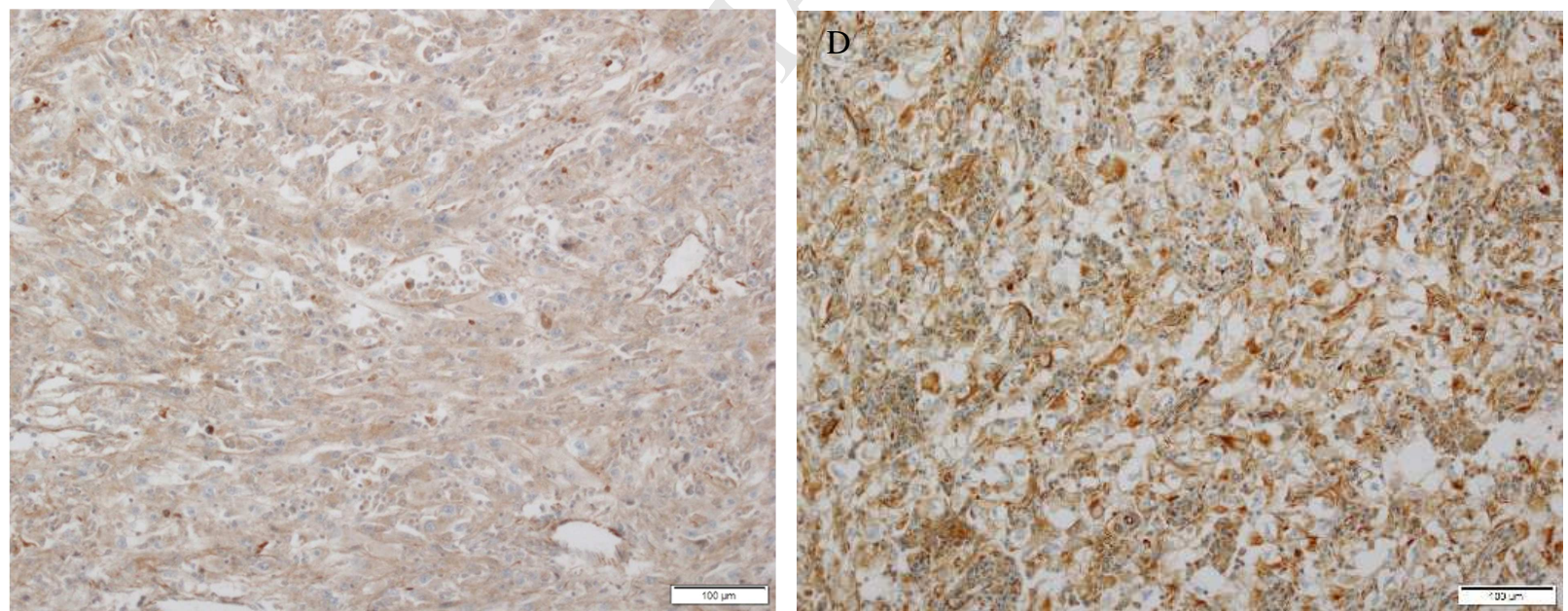
Supplementary figure: Kaplan Meier curve representing progression-free survival (PFS) and overall survival (OS) according to PD-L1 intensity

PFS: Median survival: 8 vs 17 months ( $\mathrm{p}=0.27$ ), OS: Median survival: 18 vs 29 months ( $\mathrm{p}=0.30$ )
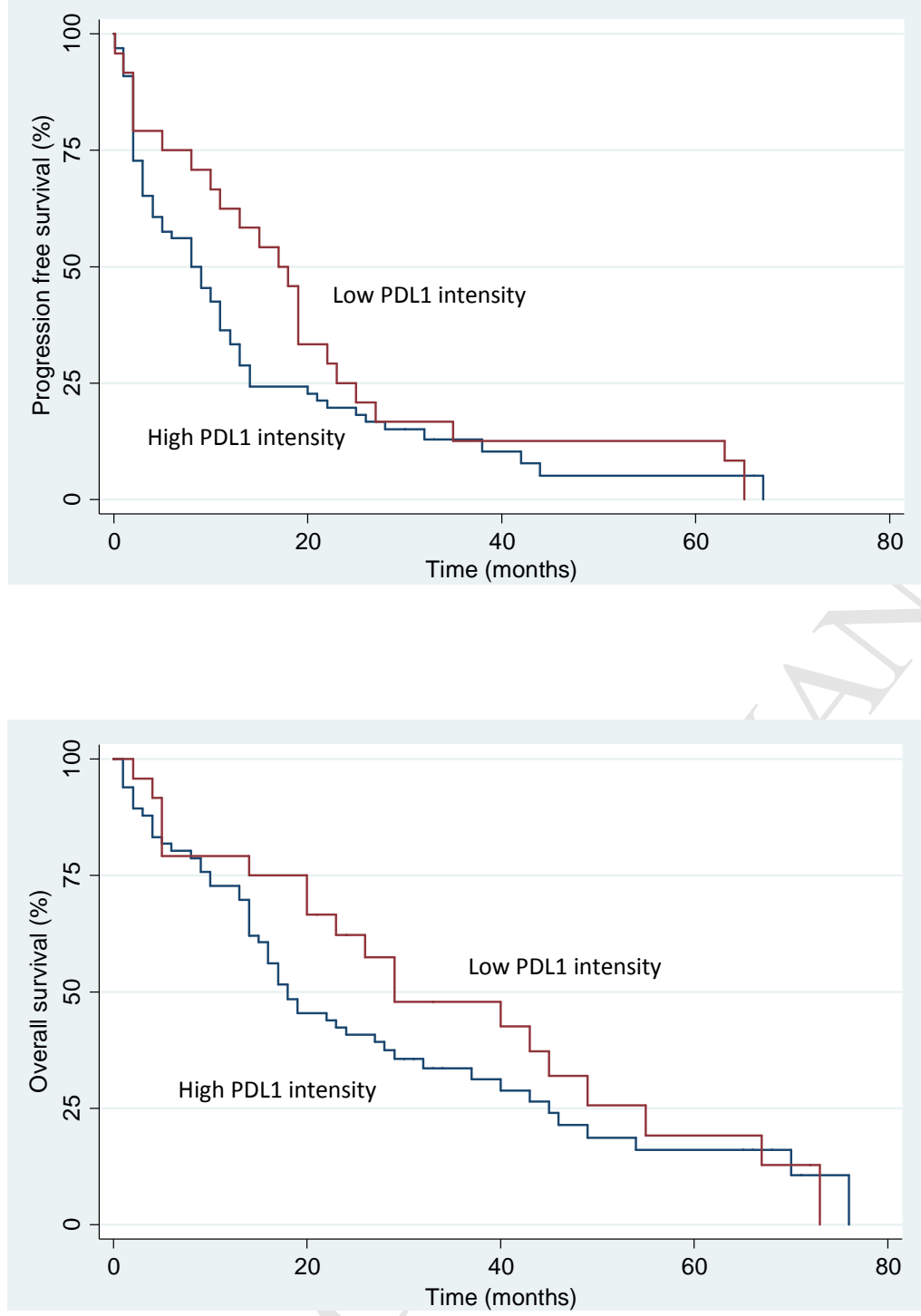